
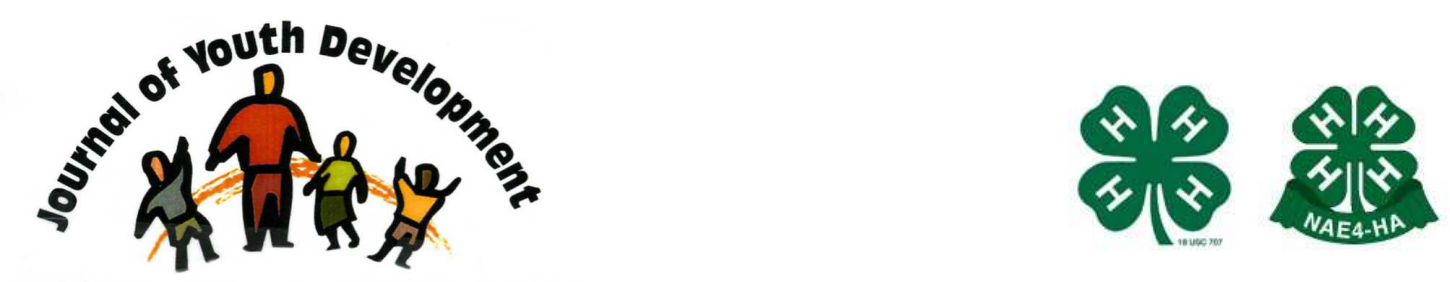

Bridging Research \& Practice

\title{
Windows of Opportunity: Family Systems Theory and Developmental Considerations for Supporting Youth, Parents and Clinicians in the Digital Age
}

\author{
Steven Barreto \\ Bradley Children's Hospital \\ 1011 Veterans Memorial Parkway \\ East Providence, RI \\ sbarreto@lifespan.org \\ Sue K. Adams \\ Brown University \\ University of Rhode Island \\ Kingston, RI \\ suekadams@mail.uri.edu \\ Jennifer Daly \\ University of Rhode Island \\ Kingston, RI \\ jdaly1221@hotmail.com
}




\title{
JOURNAL OF YOUTH DEVELOPMENT \\ bridging research and practice

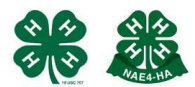

Volume 9, Number 1, Special Edition 2014

Article 140901FA001

\section{Windows of Opportunity: Family Systems Theory and Developmental Considerations for Supporting Youth, Parents and Clinicians in the Digital Age}

\author{
Steven Barreto \\ Bradley Children's Hospital \\ Sue K. Adams and Jennifer Daly \\ University of Rhode Island
}

\begin{abstract}
Digital technology use is an integral part of children's and adolescent's lives. With the rapid evolution of technology, adult caregivers can easily feel overwhelmed by the daunting task of setting boundaries on technology use. Family systems theory offers a unique perspective for understanding how external factors (i.e., technology) can impede or enhance the family system, particularly when integrated into a developmental framework. Five clinical concepts are presented that weave together developmental tasks and family systems theory. This paper offers recommendations for clinicians to help parents understand the potentially harmful consequences of technology use across the developmental spectrum. We also provide recommendations for how to support parents in discussing technology use with their children and adolescents. Lastly, we offer suggestions for how the impact of technology use on development can be integrated into human service courses at the university level.
\end{abstract}

\section{Introduction}

Advances in digital technology have quickly become integral to children's lives. The pace of technological innovation has surpassed the digital knowledge-base of many parents and educators while the advent of portable technology has made instant digital connection and immediate access available in any setting. Moreover, as technology plays an ever increasing role in youth's social interactions, the focus of concern no longer rests solely on digital media consumption, and implications for development become more numerous and complex. It is important for parents and caregivers to keep an open dialogue with their children about their 
digital technology habits and internet behavior. This dialogue should begin as soon as the child begins using technology, with the hope that children will become increasingly mindful of their technology use, with opportunities to revisit the discussion over time, using concepts appropriate to developmental stages. A developmentally informed approach could help clinicians to guide parents to maximize the benefits of digital media and avoid pitfalls such as digital dependence, an imbalance between virtual and actual worlds, reckless sharing of information in public forums, plagiarism, and cyber-bullying behavior.

\section{Rates of Technology Use in Children and Adolescents}

The statistics tell the story of an exponential increase in digital technology use among children and adolescents:

- In 2004, 39\% of teens owned a cell phone. By 2011 the rate of ownership had risen to between 77\% (Lenhart, 2012) and 86\% (Englander, 2011).

- The average age a child receives a cell phone is between 9 and 10 years old and dropping (Nielsen, 2009). Now $18 \%$ to $20 \%$ of third graders and $25 \%$ to $26 \%$ percent of fourth graders have their own cell phone (Englander, 2011).

- By middle school cell phone ownership jumps to $83 \%$ to $84 \%$, and $90 \%$ of middle schoolers can use their cell phone to text and go on the internet (Englander, 2011).

- Texting has become the number one form of communication for teens, with $63 \%$ texting daily (Lenhart, 2012). On average, teens send or receive 3,339 texts each month. When looking at only female teens, the rate rises to 4,050 texts per month (Nielsen, 2010).

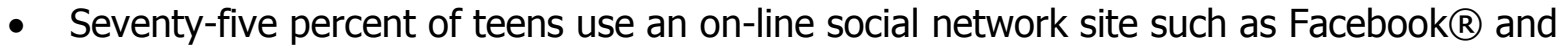
$41 \%$ own a "smart" phone that lets them check their social network sites and access the internet while mobile (Rideout, 2012).

- In a 2012 study of teens' social media use, $41 \%$ of teens described themselves as "addicted" to their cell phone (Rideout, 2012).

- When combining all forms of digital media (computer, TV, cell phone, portable digital audio device, computer games), children ages $9-18$ are plugged-in for over 10 hours a day (Rideout, Foehr, \& Roberts, 2010).

Technological advances continue to push the boundaries of access for this demographic, with smart phones linking youth to the world-wide web through text, photo, and video sharing and immediate sequential digital video transmission enabling them to transmit and interact through visual images of themselves on their portable devices from any location (e.g. ooVooß). Understanding age-related trends in technology use and their unique implications for each stage of youth development is essential for helping children and families successfully navigate a world in which children's frequent engagement with digital technology is increasingly the norm.

\section{Family Systems Theory: A model for understanding the role of technology in context} It has been observed that there is little research on how families use or are influenced by the media because it is, quite simply, a moving target (Coyne, Bushman, \& Nathanson, 2012). The rapid pace of technological innovation has outstripped the research and clinical community's capacity to accurately identify and track the quality and quantity of usage. Consider the virtual transformation of pre-teen and teen communication that has occurred in a few years as cell phone verbal contact was eclipsed by smart phone digital contact (i.e. texting).

Scholars have only begun to identify theoretical conceptualizations that can inform research, public education and clinical practice, regarding children, families and digital media. We suggest 
that it is reasonable to assume that digital technology both reflects and shapes a broad range of family system dynamics. As such, family systems theory may be a useful conceptual tool for human service and clinical professionals caring for and working with children and their families. The family is a structure of related parts or subsystems with each action or change affecting every other person in the family. While individuals make up a family system the family system is a complex whole that cannot be understood by examining members separately. Family Roles are constructed through patterns of interaction and become ingrained habits that make change difficult. Each family has invisible rules, attitudes, and communication patterns that are selfregulating and peculiar to itself; thus defining the family's boundaries. Despite resistance to change, each family system constantly adapts to maintain itself in response to its members and environment (Kerr, \& Bowen, 1988).

We propose that the emergence of parental roles regarding children's use of technology (invisible patterns of interactions, attitudes and beliefs) are strongly influential to the negotiation of these developmental challenges. This paper represents a clinically-minded effort toward the integration of family systems theory with specific tasks of child development and specific parental functions derived from the research of parental monitoring and parent-child media communication. Throughout this paper we will attempt to identify the following clinically useful concepts that represent the intersection of these theoretical conceptualizations:

1) parental roles,

2) active mediation between the child and the media content (formerly viewed as parental monitoring),

3) the assessment of boundaries, privacy and related attitudes, beliefs and system dynamics,

4) intimacy and relationship maintenance, and

5) Eriksonian developmental tasks of mastery, competence and identity exploration.

We believe these constructs lend themselves to assessment, education, and treatment across a wide range of modalities (Family Systems, Cognitive Behavioral, Social-Ecological). These constructs may have differential impact upon stages of child development, which can inform the choices of interventions made by therapists, as well as the mode of therapeutic communication.

\section{Technology use among school-age children}

If therapists can routinely assess parental roles regarding discipline and affection in school-age families, what would prevent them from assessing parental roles around digital communication? Along with asking themselves, who is responsible for discipline and who for meeting nurturance needs; they may ask themselves who in the family is responsible for purchasing, installing, operating and educating about the function of digital media? How are children introduced to digital media? Many families treat digital media with no more thought than another battery operated toy during the school-aged years and report no knowledge of tools designed to rate digital media for content or other parental monitoring tools (Mezsaros, 2004). Parents may be uncomfortable with the role of technology "educator" and family systems must shift allocation of time and resources. This may be an additional and unexpected burden requiring families to reorganize patterns of communication and sub-system boundaries.

We would suggest that digital media be viewed as an initiation into a digital world of interactions that will soon permeate the boundaries that separate the family from the outside community. Another concept related to parental roles that is crucial to this developmental period is that of parental monitoring (Coyne, Bushman, \& Nathanson, 2012). Recently, the small literature on digital media and the family has contributed a number of studies on one aspect of parental 
monitoring, which has been termed mediation (Dishion, \& McMahon, 1998). Mediation refers to a broad range of parental monitoring including

1. the extremes of restrictive mediation or strict rules on time and content without discussion and,

2. co-watching without clear rules on time and content but also devoid of discussion.

The middle position is described as active mediation and has been conceptualized to include a variety of discussion-based behaviors by parents, including evaluative statements about the acceptability of behaviors portrayed on television, conversations about the technical aspects of television, and promotion of critical viewing that discounts the reality of television (Ruh Linder, \& Werner, 2012, p. 490).

Researchers suggest that mediation may serve as a buffer against the harmful effects of digital media. Active mediation has been shown to be associated with the child's increased skepticism about TV content, reduced physical and relational aggression (through moderating against the influence of exposure to media upon positive attitudes toward aggression), as well as increased resistance to advertisements when compared with restrictive mediation and co-watching (Nathanson, \& Yang, 2003; Ruh, Linder, \& Werner, 2012). The use, however, of parental contracts/agreements may or may not be consistent with a family defined by an open system. Individuals may find this level of engagement through discussion combined with limits on time and content, to be intrusive or coercive and families may be resistant. It is reasonable to suspect that communications and media exposure will be a factor in developing attitudes toward aggression in relationships, emerging attitudes toward sexual behavior, as well as stimulate consumer cravings that may shape a child's career choice and life satisfaction (Brown, Keller, \& Stern, 2009; Coyne, et al., 2011; Shrum, Lee, Burroughs, \& Rindfleisch, 2011).

In the recent text Designing Digital Experiences for Positive Youth Development: From Playpen to Playground (2012), author Marina Umachi Bers introduces the concept of constructive digital experience, where children are active producers of digital content. She argues that core programming skills (i.e. computer literacy) are analogous to music reading skills acquired while playing a musical instrument. Here children are engaged in the mastery of skills and the development of competence, consistent with Erikson's developmental stage of industry vs. inferiority. The virtual world of gaming is presented as an opportunity to engage in goal directed civic reasoning through virtual world simulation, shared spaces or digital "parks." This is contrasted with the more passive and consumerist experience of the digital "shopping mall," where the child learns to operate the game, but is not stimulated to engage in creating interactive worlds that demand social interactive skills (e.g. conceiving of a shared space with mutual goals and agreed-upon rules), or in acquiring core skills (e.g. programming) that can be a foundation for digital learning and problem-solving in later years. In her book, Bers provides educational rubrics for assessment and case examples of children developing these skills through digital experience. She has also designed interactive digital curriculum for young children which she presents in her book, Blocks to Robots: Learning With Technology in the Early Childhood Classroom (2008).

\section{Clinical objectives when working with school-aged children and their families}

The developmental goal for the school-age child is to strengthen the emergence of real world skills and sense of competence and to establish themselves in the social arena of peers through play and games that involve planning and strategy, interest in collections or hobbies, habits for self-regulation and learning (homework, chores, increasing responsibility for organizing school materials) (commonsensemedia.org). Therefore, when working with the parents of school-age 
children around digital and screen time management, the goal should be to strengthen the child's capacity for self-regulation: attention, memory, behavioral inhibition, adaptability to change (e.g. transitions) and reading skills (Garon, Bryson, \& Smith, 2008; Karreman, van Tuijl, van Aken, \& Dekovic, 2006; Kopp, 1982; McLelland, et al., 2007). While closely managed digital technology presents opportunities for learning and recreational experiences, the risk is that excessive digital screen dependence can lead to overexposure, intense arousal, poor regulation, and less reading time. One area of concern for younger school-age child is that TV and other screen media may accompany a reduction in time co-reading or reading on one's own, an activity critical to children's cognitive, language and writing skill development (Thompson, Adair, \& Bentley, 2013). Parents should avoid inconsistent screen time use and should keep to timelimits.

The primary function of technology should not be to sooth or distract the child. When parents share the interest and the joy, and comment, they become co-participants and there are more opportunities for learning benefits, as well as strengthening the parent-child relationship (Linebarger, \& Vaala, 2010). Additionally, parents can set in place early habits of screen time including use in only the public areas of house. Parents should begin to track all forms of screen time (TV, computer learning programs, handhelds, phone screens) to pre-determine just how much is enough. Parents can create opportunities for controlled transitions and cue children in advance. Like any preferred activity, digital time can be an effective response cost tool for discipline when used consistently.

Recently, in an on-line publication by Common Sense Media, titled "Power Up: Apps for Kids with Special Needs and Learning Differences," many apps are reviewed and catalogued with descriptions suggesting cognitive and learning benefits (Bowser, n.d.). The empirical support for these descriptions is unclear. On-line position papers can be helpful in assessing such claims and guiding the selection of games for children (e.g., The National Association for the Education of Young Children and the Fred Rogers Center for Early Learning and Children's Media, 2012). Shore (2008) points out that most research evidence in children concerns the impact of digital games on visual attention. She cites several studies suggest that game use is associated with greater capacity for rapid shifts in attention, faster reaction times, increased eye-hand coordinator and improved manual dexterity. There is also some evidence for improvements in mental rotation and spatial visualization. Clearly more research is needed to transfer to realworld settings and ecologically valid tasks. Shore points out, however, that the research findings were substantial enough that the American Medical Association concluded that, while some research suggested video game usage as risk factor for ADHD, there were other studies suggesting digital media may be useful treatment. She cites studies that propose some interesting questions about more complex cognitive functions. For example, do games with complex dynamics (such as SimCity), lead to more or less complex thinking? Are children exposed to digital media processing information qualitatively differently (e.g. the text now illuminates the graphics) when compared the non-digitally exposed children of the past. Shore also cited studies suggesting that digital media may increase Verbal and Performance IQ scores in adults with TBI and other impairments. The studies of children remain "small and inconclusive." Another critical question that has yet to be answered is: Does digital media increase the motivation to learn?

Children can also become overly dependent upon video games as primary source of play, fantasy, leading to an avoidance of social interaction with peers and adults, the impulsive use of technology without regard for safety risks (Gentile, 2009) as well as obesity and other health conditions associated with sedentary gaming. Active gaming represents an innovative use of 
digital technology to promote health and fitness through increasing the amount of time spent in physical activity, exercise and play. These include Exergames such as rhythmic dance games, virtual bicycles, virtual sport and balance board simulators (e.g. Wii). Interactive fitness activities include digital on-screen instruction, light pattern games and martial art simulators. These games are meant to be a compliment to traditional physical activity and may motivate children to be more active (Hanse, \& Sanders, 2011).

\section{Introduction of the Family Media Agreement}

This is the optimal stage to introduce the family media agreement (commonsensemedia.org). The agreement is a written guide, which can be tailored to the unique preferences of the family and can help both the child and parent organize and prioritize shared expectations that lead to a common goal of personal safety and emotional health. Children at this stage are very aware of rules and respond well to clear expectations. Children can agree not to share passwords with anyone other than parents and to never give out personal information such as their birthday. Children should agree to tell their parents if anything on the internet seems inappropriate or makes them feel distressed. This is the time to introduce the concept that not everything they read or see on the internet is true. Clinicians can introduce parents to the concept of media ratings (commonsensemedia.org) as a shared family activity. Parents and children can together look up a movie or game, find the ratings for violence, sexual content, or even product placement, and discuss with their parents whether or not the content is appropriate. This type of activity increases their sense of competence and strengthens children's commitment to selfcontrol in media habits and reflection upon media. If children receive a cell phone during this period, parents should be encouraged to disengage the camera and purchase a phone without options for internet access. This will make it easier to keep digital media use in the public areas of the house. Parents and children can also engage in shared conversations about technology as email accounts are created, computer privacy settings and passwords are established, and portable game and cell phone technology are initiated.

\section{Technology use in Pre-Teens}

The Pre-Teen world is an exciting one of new opportunities and passionate need to be accepted and connected. Digital media can provide opportunities for creating and exploring identity (Bers, 2012) and social connection (Strayhorn, 2012; Valkenberg, \& Peter, 2009). During the pre-teen years identity is fragile and subject to social comparison and peer group dynamics. Children at this stage define themselves by visible markers such as appearance, clothes, physical attributes, athletic competence, extracurricular activities such as performance arts, as well as digital media interests such as music, film or television celebrities, digital games and gaming. The developmental challenge of the pre-teen years is the uneven pattern of emerging abilities. At times pre-teens may appear to understand cause and effect reasoning and to have the ability to independently project consequences into the future and take the perspective of others. At other times they can demonstrate lapses in impulse control, judgment and communication skills that, when combined with rapid identity shifts, can place their social reputation at risk, threaten their personal safety or lead to behaviors that can be socially devastating to others (Spear, 2000). Parents may experience role conflict, particularly those in open family systems, and may find themselves drifting away from actively mediation and from managing digital technology, as they see their Pre-teen's speed of navigation and "technology savvy" and conclude that this is a good time to leave their preteen alone to navigate the digital world, in the name of promoting independence (Yardi, \& Bruckman, 2011).

As the pre-teen's identity emerges, it can be closely connected to their digital experience. The rapid shifts and storms of this period, can impact the family system. The system can respond by 
over-constraining digital experimentation of identity or by little to no acknowledgement of this process. Pre-teens can move too rapidly away from identification with adult family members who may represent a closed family system that has engaged in more restrictive mediation during the school-age period. Pre-teens can quickly immerse themselves in developing digital personae that, if unmonitored, are more likely to lead to greater risk of digital harm through sharing of information, receiving unwelcome digital interactions or pre-teen harassment. Another problem is the concealment of identity or anonymity. While this can promote experimentation, it can also lead to disinhibition and digital aggression (Hertlein, 2012; Kowalski, Limber, \& Agatston, 2012).

Bers (2012) suggests this is also a time of potential digital exploration of identity and developing the ability to "sustain loyalties despite value systems that might be confusing and contradictory." She points out that social network sites or "wireless hangouts" and many of the popular interactive games do not, by themselves, facilitate the type of identify exploration that promotes positive development. She has designed digital platforms and games (e.g. Zora) with the specific intent of exploring different styles of character traits and values through virtual communitybuilding, communication, collaboration, and content creation. However Bers also offers examples of students developing collaboration and communication skills through more conventional digital games (e.g. World of Warcraft).

\section{Clinical objectives when working with pre-teens}

This is the developmental stage where the concept of privacy and related attitudes and beliefs regarding boundaries emerge as useful clinical concepts. Here the access to the world outside the family can still be partially restricted, while there is still time for discussion of the Pre-Teens experience of digital worlds and digital relationships. If boundaries, however, are rigid between the family and the outside world, this can lead to role-strain, conflict and isolation for the PreTeen who wishes greater access or who is overly exposed to digital media through peers around the school or extracurricular environment.

This is the time for parents to use the foundation of the open dialogue and re-convey interest in their preteen's activities, such as asking them to show them how to use online tools, guiding them through their favorite websites, etc. The clinician may encourage parents to remain calm, persistent and alert for opportune moments, which will help to weather the storms of protest and emerging adolescent prickliness about conversations. The concept of privacy may be helpful to explore with parents at this stage, as they may struggle with the tension between allowing for greater privacy while maintaining adequate safety protection. Parents may benefit from exploring how to determine if a review of their child's emails, texts and posts is warranted. A practical discussion of the use of social media with a parent can help them sort out how to be involved in their children's social networking sites as an adult participant, while maintaining parent-child boundaries and creating opportunities for mutual dialogue and discussion about digital citizenship. Parents may need to re-visit questions about the use of parental controls or monitoring programs and devices. Parents should be alert to their child's obsessive behavior at this age with digital media and poor emotion regulation and self-care including a compulsion to stay digitally connected that may lead to sudden changes in mood (anxiety, depression), sleep loss, temper tantrums tied to media usage and transitions (King, Delfabbro, \& Griffiths, 2012).

This is a time to stress the concept of self-control in conversations (e.g. "you control your media; it does not control you") and the rule of thumb: "If you can't say it in person, don't post it." Parents can ask their Pre-Teen questions that promote reflection on the importance of impulse control (Can they agree never to enter a chat room where strangers may be communicating with them? Can they pause or "think before they press send") and judgment (Do 
they understand that there is no internet privacy once information has been shared, that texts and posts last forever and can be replicated and taken out of context? Do they know about cyberbullying and harassment and know what to do about it when they see it happening to others or when they are the victims?) This is also a time for open dialogue about problemsolving strategies and scenarios that help the pre-teen to project information into an unforeseen digital future and reason-out what potential consequences may lay in wait for them. The digital media agreement can be upgraded, to include a conversation about the risk of nude or sexually explicit photos or pictures, blocking inappropriate messages, telling parents if something makes them feel uncomfortable and an emerging sophistication about the management of personal privacy controls including being wary of sites that ask them to disclose or share personal information.

\section{The importance of monitoring technology use in the home}

Despite the fact that many caregivers do their best to keep up with technology and create a safe technological environment for their children, the technological savy of today's youth can quickly outpace that of their parents. For example, parents are often shocked to learn that the access that is prohibited on the family computer is completely enabled by the WiFi and the IPOD in the bedroom. Ideally, clinicians should encourage parents to keep digital media in a centralized and public area of the home. This will allow the parents to better track the types of information that are being accessed by their children. Parents should also require that youth and adolescents "turn in" their phones and devices at the end of the night. It has been well documented that adolescents use technology well into the evening hours, which interferes with both their sleep onset and sleep maintenance (e.g., Van den Bulck, 2007; Munezawa, et al., 2011). Many adolescents sleep with the phones close to their bed or under their pillow and wake up after sleep onset to read and answer texts (Adams, \& Kisler, 2013). These multiple nighttime awakenings can result in daytime symptoms such as inattention, difficulty concentrating, and mood dysregulation (Owens, 2005). Late night interactive gaming can also causes similar delays in sleep onset and daytime difficulties. Exposure to violent video games and movies also have the added risk of increasing physiological arousal, aggression-related thoughts and feelings, aggressive behavior, as well as decreasing overall prosocial behavior and academic performance (Anderson, \& Bushman, 2001; Sharif, \& Sargent, 2006). As such, a "turn in" policy will help parents to control unmonitored use at night.

\section{Technology use in Young-adults}

The teenage and young adult years are characterized by a need to foster independence across multiple domains, including social, health, academic, recreational and employment (Lloyd, Dean, \& Cooper, 2007). For most teens, a strong desire for independence is coupled with the view that peer groups are more important and influential than parents. In the teenage and young-adult years, parents hope that their efforts to promote healthy digital citizenship have been internalized by their teens. Many parents may find themselves drifting further away from active mediation in an effort to encourage and support independence.

New clinical and developmental issues begin to emerge for teens who are developing intimacy and working to maintain relationships. Teens are also experimenting with a wider array of strategies (e.g., in-person connections, sexuality, etc.) as they attempt to foster friendships and intimate social connections (Lloyd, et al., 2007). Although "high-tech" strategies can enhance connection and decrease inhibitions among family members and romantic partners, the relational literature also suggests that technology-mediated intimacy can cause tension in relationships and feelings of hurt and betrayal (Grov, Gillispie, Royce, \& Lever, 2011; Hertlein, 2012). Notably, however, despite often unlimited access to digital communication tools, $58 \%$ 
teens would miss in person interactions (more than texting or social media) should it be taken away (Ericsson, 2012).

\section{Consequences of adolescent technology use: Sexting and plagiarism}

Although youth may technically be approaching adulthood, parents should continue to have ongoing conversations about the implications of technology use. Parents should actively encourage teens to create and manage their own privacy settings, being sure to regularly check that privacy settings have not been changed by the website administrator. When making new accounts or purchasing items online, teens should be wary of giving out personal information, and they should be wary of sites that ask them to disclose or share personal information. Additionally, certain online behaviors should be considered high-risk, especially if they are capable of damaging one's reputation in both the short and long term. For instance, websites where individuals can post anonymous comments about their peers have the potential to cause psychological and social distress, particularly if these sites are used as weapons with the intent to bully, embarrass, and harass others in a public forum (Li, 2006).

Sexually-explicit photos or text messages can be particularly damaging, and parents should add "sexting" to an ongoing discussion of sexuality and general well-being. It is important for teens to understand that even if they send a sexually-explicit photo to a partner, or desired partner, once it is out of their hands it is public information (Whitaker, \& Bushman, 2009). Some teens may argue that filtering apps, such as Snap chat ${ }^{\circ}$ (which makes a photo "disappear" within a predetermined amount of seconds after being opened by the receiver), circumvent the possibility of the receiver sharing the photo without consent. However, what if the receiver allowed others to view the photo? What if the receiver took a screen shot of the photo (although Snap chat $\mathbb{R}$ will notify senders if this occurs)? And what if the sender's phone is lost or stolen with the sexually-explicit photo saved on it? In recent years, many states, such as Rhode Island, have implemented new laws allowing adolescents over the age of 18 who are in possession of nude photos of someone under the age of 18 to be charged with a felony sex offense (Rhode Island General Assembly; $\S 11-9-1.3,2011)$. It is questionable how many 18-year-old adolescents possess the ability to understand the gravity of this offense, particularly if they have been in a long-term relationship with a younger partner as they transition into adulthood.

Parents, clinicians and teachers should also explicitly discuss the temptation to use one's phone to look up answers during exams. This should include the consequences of looking up answers during an exam (i.e., with a smartphone) or plagiarizing sources that may be difficult for teachers to track. Unfortunately, many students do not understand the concept that information is intellectual property, especially if they have unlimited access to it (Pichford, 2012). As with any form of cheating, these offenses can lead to expulsion if caught. Overall, both parents and teachers should have ongoing dialogue with their children emphasizing that the internet should always be used responsibly, with integrity and not be hurtful to anyone. Before every online interaction teens should ask themselves, "would I mind if my (parent, teacher, college admissions officer, future employer, etc.) saw what I was doing?" If the answer is yes, they should take a moment to reconsider their actions.

\section{Implications for the training of human service workers}

Technology can significantly impact the developmental trajectory of children and adolescents, particularly as it pertains to their social, emotional, academic and physical well-being. To our knowledge, many university-level human service programs do not have formal mechanisms for training emerging professionals about integrating digital literacy and responsibility into their teaching and mentoring of students. Therefore, we offer suggestions for how family systems 
theory and developmental theory can inform our understanding of digital media use and curriculum development in higher education. First, it would be beneficial for educators to consider how to teach about digital citizenship within preexisting curricula. Issues related to responsible media use can be integrated as supplemental topics and readings throughout courses that focus on children, adolescent, or lifespan development. Assignments and projects could encourage students to explore websites that provide trends about technology use among youth, such as:

- Pew Internet Data

- Kaiser and Commonsense Media Data

- Foundation or national association "position papers" such as Shore's (2008) review of developmental research on effects of digital media

- Technology and Interactive Media as Tools in Early Childhood Programs Serving Children from Birth through Age 8 (2012)

- The university-based institute analysis "The True Prevalence of Sexting" (Lounsbury, Mitchell, \& Finkelhor, 2011)

Second, emerging professionals should also be made aware of pre-developed curricula that can be used as a future resource in their classrooms. For instance, commonsensemedia.org offers a wide range of programs that promote digital literacy and citizenship across the academic years. Teachers and human service workers are able to choose toolkits from a number of digital literacy domains (e.g., internet safety, cyberbullying, creative credit and copyright, etc.). There are also digital kits for parents that provide practical strategies and tools to engage in active mediation with children and teens, including interactive ratings of a wide range of digital media including film/ television, music videos, and video games. Professionals can also stay abreast of new technological developments and issues through commonsense media's active blog. Thinking more broadly, these tools can also be used to enhance communication about digital citizenship across a variety of other venues, including traditional family therapy, group prevention and education of parents and children in school settings, after-school childcare programs, and youth development organizations such as Boys and Girls Clubs and the YMCA. Finally, more technologically savvy human service instructors may choose to integrate the work Marina Umaschi Bers and her colleagues into their curriculum. Courses could include sections, laboratories or practica, where students are actively trained in models of digital environments to foster positive youth development.

\section{Conclusion}

The study of human development is a natural academic discipline for the intersection of family systems theory, child development, and empirically based communication concepts such as parental mediation. When combined, we believe that these concepts and constructs can provide a theoretical foundation for prevention and intervention human service delivery in the area of digital citizenship. Digital media is expanding rapidly and research models are struggling to maintain relevance and accuracy to the practical setting of the therapist, prevention educator, or human service worker. At the same time scholars have recently observed that there is relatively little research on how clinicians approach a child or family's media use or how prevention educators and human service workers instruct in the area of digital citizenship (Coyne, Bushman, $\&$ Nathanson, 2012). However, there are concepts that can inform clinical practice and group or individual instruction. This review represents a small step in this direction. 


\section{References}

Adams, S.K., \& Kisler, T.S. (2013). Sleep quality as a mediator between technology-related sleep quality, depression, and anxiety. Cyberpsychology, Behavior, and Social Networking, $16(1), 25-30$.

Anderson, C.A., \& Bushman, B.J. (2001). Effects of violent video games on aggressive behavior, aggressive cognition, aggressive affect, physiological arousal, and prosocial behavior: A metaanalytic review of the scientific literature. Psychological science, 12(5), 353-359.

Bers, M. Umaschi. (2012). Designing digital experiences for positive youth development: from playpen to playground. Oxford, England: Oxford University Press.

Bers, M. Umaschi. (2008). Blocks to robots: learning with technology in the early childhood classroom. New York: Teachers College Press.

Bowser, G. (n.d.). Power up: Apps for kids with special needs and learning differences. Retrieved from http://www.commonsense.org/guide/special-needs

Brown, J.D., Keller, S., \& Stern, S. (2009). Sex, sexuality, sexting, and sex-ed: Adolescents and the media. Prevention Researcher, 16(4), 12-16.

Common Sense Media for Educators. (2013). Common Sense Media Inc. Retrieved from http://www.commonsensemedia.org.

Coyne, S.M., Bushman, B.J., \& Nathanson, A.I. (2012) Media and the family: A note from the guest editors. Family Relations, 61(3), $359-362$.

Coyne, S.M., Nelson, D.A., Graham-Kevan, N., Tew, E., Meng, K.N., \& Olsen, J.A. (2011). Media depictions of physical and relational aggression: Connections with aggression in young adults' romantic relationships. Aggressive Behavior, 3入1), 56-62.

Dishion, T.J., \& McMahon, R.J. (1998). Parental monitoring and the prevention of child and adolescent problem behavior: A conceptual and empirical formulation. Clinical Child and Family Psychology Review, 1(1), 61-75.

Englander, E. (2011). Research findings: MARC 2011 Survey Grades 3-12. Bridgewater, MA: Massachusetts Aggression Reduction Center, Bridgewater State University. Retrieved from http://webhost.bridgew.edu/marc/MARC\%20REPORT-Bullying\%20In\%20Grades\%20312\%20in\%20MA.pdf

Ericsson Corporate Public \& Media Relations. (2012). Talking, texting, poking, and dating. Retrieved from http://www.ericsson.com/res/docs/2012/howteenagersareusingtechnologyintheirsociallives.pdf

Garon, N., Bryson, S.E., \& Smith, I.M. (2008). Executive function in preschoolers: A review using an integrative framework. Psychological Bulletin, 134(1), 31-60.

Gentile, D. (2009). Pathological video-game use among youth ages 8 to 18: A national study. Psychological Science, 20(5), 594-602. 
Grov, C., Gillspie, B., Royce, T., \& Lever, J. (2011). Perceived consequences of casual online sexual activities on heterosexual relationships: A U.S. online survey. Archives of Sexual Behavior, 40(2), 429-439.

Hansen, L., \& Sanders, S.W. (2011). Active gaming: A new paradigm in childhood physical activity. Digital Culture \& Education, 3:2, 123-139.

Hertlein, K.M. (2012). Digital Dwelling: Technology in couple and family relationships. Family Relation, 61(3), $374-387$.

Karreman, A., van Tuijl, C., van Aken, M.A.G., \& Dekovic, M. (2006). Parenting and selfregulation in preschoolers: A meta-analysis. Infant and Child Development, 15(6), 561-579.

Kerr, M., \& Bowen, M. (1988). Family Evaluation. New York: W. W. Norton.

King, D.L., Delfabbro, P.H., \& Griffiths, M.D. (2012). Clinical interventions for technology-based problems: Excessive internet and video game use. Journal of Cognitive Psychotherapy, 26(14), 43-56.

Kopp, C.B. (1982). Antecedents of self-regulation: A developmental perspective. Developmental Psychology, 18(2), 199-214.

Kowalski, R., Limber, S., \& Agatston, P. (2012). Cyber-bullying: Bullying in the digital age. New York, NY: Wiley.

Lenhart, A. (2012). Teens, smartphones \& texting. Washington, D.C. Pew Internet \& American Life Project. Retrieved from http://pewinternet.org/Reports/2012/Teens-andsmartphones.aspx?src=prc-headline

Li, Q. (2006). Cyberbullying in schools: A research of gender differences. School Psychology International, 2オ(2), 157-170.

Linebarger, D.L., \& Vaala, S.E. (2010). Screen media and language development in infants and toddlers: An ecological perspective. Developmental Review, 30, 176-202.

Lloyd, J.M., Dean, L.A., \& Cooper, D.L. (2007). Students' technology use and its effects on peer relationships, academic involvement, and healthy lifestyles. NASPA Journal, 44(3), 481-489.

Lounsbury, K., Mitchell, K.J., \& Finkekhor, D. (2011). The true prevalence of sexting [Fact sheet]. Retrieved from http://www.unh.edu/ccrc/pdf/Sexting\%20Fact\%20Sheet\%204 29 11.pdf

McLelland, M.M., Cameron, C.E., Connor, C.M., Farris, C.L., Jewkes, A.M., \& Morrison, F.J. (2007). Links between behavioral regulation and preschoolers' literacy, vocabulary, and math skills. Developmental Psychology, 43(4), 947-959.

Meszaros, P.S. (2004). The wired family: Living digitally in the post-information age. American Behavioral Scientist, 48(4), 377-390. 
Munezawa, T., Kaneita, Y., Osaki, Y., et al. (2011). The association between use of mobile phones after lights out and sleep disturbances among Japanese adolescents: A Nationwide cross sectional survey. Sleep, 34(8), 1013-1020.

Nathanson, A.I., \& Yang, M. (2003). The effects of mediation content and form on children's responses to violent television. Human Communication Research, 29(1), 111 - 134.

National Association for the Education of Young Children \& Fred Rogers Center. (2012).

Technology and interactive media as tools in early childhood programs serving children from birth through age 8: A joint position statement issued by the National Association for the Education of Young Children and the Fred Rogers Center for Early Learning and Children's Media. Retrieved from: http://issuu.com/naeyc/docs/ps technology issuu may2012/1.

Nielsen. (2009). Mobile Kids Insights Q1. New York, NY: Author.

Nielsen. (2010). Mobile Youth Around the World. New York, NY: Author.

Owens, J. (2005). The ADHD and sleep conundrum: A review. Journal of Developmental and Behavioral Pediatrics, 26(4), 312-322.

Pichford, K.T. (2012). Mouse click plagiarism: Can technology help to fight back? Practitioner Research in Higher Education, 6(2), 58-68.

Rhode Island General Assembly. (2011) Title 11 Criminal Offenses, 11-9-1.4 Minor electronically disseminating indecent material to another person - "Sexting" prohibited. Retrieved from http://www.rilin.state.ri.us/Statutes/TITLE11/11-9/11-9-1.4.HTM.

Rideout, V. (2012). Social media, social life: How teens view their digital lives. San Francisco, CA: Common Sense Media. Retrieved from http://www.commonsensemedia.org/sites/default/files/research/socialmediasociallife-final061812.pdf

Rideout, V.J., Foehr, U.G., \& Roberts, D.F. (2010). Generation M2: Media in the lives of 8-to 18year-olds. Menlo Park, CA. Kaiser Family Foundation.

Ruh Linder, J., \& Werner, N. (2012). Relationally aggressive media exposure and children's normative beliefs: Does parental mediation matter? Family Relations, 61(3), 488 - 500.

Sharif, I., \& Sargent, J.D. (2006). Association between television, movie, and video fame exposure and school performance. Pediatrics, 118(4), e1061-e1070.

Shore, R. (2008). The power of pow! wham!: Children, digital media \& our nation's future: Three challenges for the coming decade. New York, NY: The Joan Ganz Cooney Center at Sesame Workshop. Retrieved from: http://www.joanganzcooneycenter.org/

Shrum, L.J., Lee, J., Burroughs, J.E., \& Rindfleisch, A. (2011). An online process model of second-order cultivation effects: How television cultivates materialism and its consequences for life satisfaction. Human Communication Research, 371), 34-57. 
Spear, L.P. (2000). The adolescent brain and age-related behavioral manifestations. Neuroscience and Biobehavioral Reviews, 24(4), 417-463.

Strayhorn, T.L. (2012). Exploring the impact of Facebook and Myspace use on first-year students' sense of belonging and persistence decisions. Journal of College Student Development, 53(6), 783-796.

Thompson, A.L., Adair, L.S., \& Bentley, M.E. (2013). Maternal characteristics and perception of temperament associated with infant TV exposure. Pediatrics, 131(2), e390-e397, doi: 10.1542/peds.2012-1224

Valkenburg, P.M., \& Peter, J. (2009). Social consequences of the internet for adolescents: A decade of research. Current Directions in Psychological Science, 18(1), 1-5.

Van den Bulck, J. (2007). Adolescent use of mobile phones for calling and sending text messages after lights out: Results from a prospective cohort study with a one-year follow up. Sleep, 30(9), 1220-1223.

Whitaker, J.L. \& Bushman, B.J. (2009). Online dangers: Keeping children and adolescents safe. Washington and Lee Law Review, 66(3), 1053-1063.

Yardi, S., \& Bruckman, A. (2011). Social and technical challenges in parenting teens' social media use. Proceedings of the SIGCHI Conference on Human Factors in Computing Systems, 3237-3246. doi: 10.1145/1978942.1979422.

(C) Copyright of Journal of Youth Development Bridging Research and Practice. Content may not be copied or emailed to multiple sites or posted to a listserv without copyright holder's express written permission. Contact Editor at: patricia.dawson@oregonstate.edu for details. However, users may print, download or email articles for individual use.

ISSN 2325-4009 (Print); ISSN 2325-4017 (Online) 